\title{
Características fisiológicas e anatômicas de plantas de sibipiruna submetidas à hipoxia
}

\author{
Physiological and anatomical characteristics of Sibipiruna plants under hipoxia
}

\author{
Paôla de Castro Henrique ${ }^{\mathrm{I}}$ José Donizeti Alves ${ }^{\mathrm{I}}$ Patrícia de Fátima Pereira Goulart ${ }^{\mathrm{II}}$ \\ Sidnei Deuner ${ }^{\mathrm{III}}$ Neidiquele Maria Silveira ${ }^{\mathrm{IV}}$ Ilisandra ZanandreaV $^{\mathrm{V}}$ \\ Evaristo Mauro de Castro ${ }^{\mathrm{VI}}$
}

RESUMO

Plantas em seu ambiente natural estão sujeitas a condições adversas, passando por períodos de estresse breves ou duradouros. Algumas espécies desenvolvem mecanismos que as fazem suportar as condições adversas, permitindo sua sobrevivência. O objetivo deste estudo foi avaliar as respostas fisiológicas e anatômicas no desenvolvimento inicial de plantas de sibipiruna submetidas à hipoxia. Plantas com três a quatro folhas completamente expandidas foram submetidas a três tratamentos: plantas sem alagamento, alagadas nas raízes $e$ totalmente alagadas. Foram realizadas avaliações dos teores de amido, açúcares solúveis totais e redutores em folhas e raízes coletadas a cada cinco dias, durante 30 dias. Características anatômicas foram avaliadas 15 dias após o início de cada tratamento. A maior redução nos teores de amido nas folhas e raízes foi observada nas plantas totalmente alagadas. Para açúcares solúveis totais e redutores, foi observado comportamento semelhante ao obtido em amido; porém, as plantas alagadas nas raízes apresentaram, em alguns períodos de avaliação, teores, principalmente nas raízes, superiores aos observados nas plantas sem alagamento. Essas plantas também apresentaram maior densidade estomática em relação aos demais tratamentos. Para a espessura do córtex e do cilindro vascular das raízes, foi observada uma redução para os tratamentos alagados, cujas plantas totalmente alagadas apresentaram uma maior barreira apoplástica imposta pelo espessamento em fi caracterizada pela formação de septos nas células próximas à endoderme.

Palavras-chave: Caesalpinia peltophoroides, alagamento, carboidratos, espessamento fi.

\section{ABSTRACT}

Plants in their natural environment are subject to adverse conditions, and the stress periods can be short or long. Some species develop mechanisms that make them bear the adverse conditions, allowing their survival. The aim of this study was to evaluate the anatomic and physiological responses in the initial development of Sibipiruna plants submitted to hypoxia. Plants with three to four leaves fully expanded were subjected to three treatments: plants without flooding, flooded on roots and totally flooded. Evaluations were carried out in the starch, total soluble sugars and reducing sugars levels in the leaves and roots collected every five days, for 30 days. Anatomical characteristics were evaluated 15 days after the beginning of each treatment. The largest reduction in starch level in leaves and in roots was observed in plants completely flooded. For total soluble sugars and reducing sugars were observed behavior similar to that achieved in starch However, the plants which had flooded roots, in some periods of assessment, had levels, mainly in the roots, higher than the plants without flooding. These plants also showed higher stomatal density than the other treatments. For the thickness of the cortex and the cylinder vascular roots, a reduction was observed for the flooded treatment, which completely flooded plants had a higher apoplastic barrier imposed by thickening in phi, which is characterized by the formation of septa in cells near the endodermis.

Key words: Caesalpinia peltophoroides, flooding, carbohydrates, phi thickenings.

\footnotetext{
ISetor de Fisiologia Vegetal, Departamento de Biologia, Universidade Federal de Lavras (UFLA), Lavras, MG, Brasil.

IICentro Universitário de Lavras (UNILAVRAS), Lavras, MG, Brasil. E-mail: patriciagoulart@unilavras.edu.br.

IIIInstituto de Biologia, Universidade Federal de Pelotas (UFPel), CP 354, 96010-900, Pelotas, RS, Brasil. E-mail: sdeuner@yahoo.com.br. Autor para correspondência.

IVUFLA, Lavras, MG, Brasil.

vEMBRAPA Clima Temperado, Pelotas, RS, Brasil.

${ }^{\mathrm{VI}}$ Departamento de Biologia, UFLA, Lavras, MG, Brasil.
} 


\section{INTRODUÇÃO}

A formação de barragens em cursos d’água é uma prática comum em todo o mundo e tem o objetivo que varia desde a geração de energia elétrica, irrigação e navegação até o turismo e esporte. Entretanto, a variação anual do nível da água entre as cotas mínimas e máximas de operação das represas leva a formação de uma faixa de solo geralmente desnuda, ou com pouquíssima vegetação herbácea, denominada faixa de depleção (SALVADOR, 1986). Assim, para que esses lagos tenham a maior vida útil possível, torna-se importante a presença de ecossistemas ciliares, oriundos da revegetação dessas áreas de depleção. Essa estratégia de contenção do impacto ambiental é importante, pois, além de manter a qualidade e o volume da água pelo tamponamento dos cursos d'água e as áreas adjacentes cultivadas, retém grande quantidade de sedimentos, defensivos agrícolas e nutrientes, protege o solo contra os processos erosivos e aumenta a capacidade de infiltração de água no solo.

Em áreas alagadas ou sujeitas ao alagamento temporário, a difusão de gases da atmosfera até o solo é fortemente afetada, e as trocas gasosas são reduzidas a níveis extremamente baixos (JACKSON \& COLMER, 2005). A sobrevivência das plantas depende, dentre outros fatores, da sua capacidade de crescimento e distribuição de nutrientes inorgânicos, água e fitormônios para os ramos e outros drenos. Entretanto, o alagamento do solo pode causar redução na taxa de translocação de carboidratos das folhas para as raízes, diminuindo seu crescimento e suas atividades metabólicas, que passam a demandar menor quantidade de carboidratos, acumulando os fotossintatos nas folhas. Dessa forma, a maior disponibilidade de substrato respiratório, como a glicose, pode ser determinante na sobrevivência dos tecidos das raízes em ambientes anóxicos (DIAS-FILHO, 2006).

Outro fator importante deve-se à diversidade de mecanismos que as plantas desenvolvem como adaptações morfológicas, metabólicas e anatômicas mediante o alagamento e a superação da falta de oxigênio no sistema radicular (ZENZEN et al., 2006). Espécies mais adaptadas geralmente evitam a hipoxia, desenvolvendo um eficiente transporte de oxigênio da parte aérea até as raízes submersas por meio da formação de aerênquimas, raízes adventícias, hipertrofia do caule e produção de lenticelas (SCHAFFER et al., 1992). A tolerância a essas condições varia, também, com a idade e o tempo de exposição ao alagamento, de forma que, geralmente, o estresse por inundação reduz a diversidade de espécies nas margens dos rios e reservatórios (CAPON, 2005).
A sibipiruna (Caesalpinia peltophoroides Benth.) é uma planta originária do Brasil e muito utilizada em paisagismo urbano em geral, sendo também indicada para plantios mistos em áreas degradadas de preservação permanente (LORENZI, 2002). Nas regiões de revegetação ciliar do Alto Rio Grande (MG), essa espécie tem se apresentado como tolerante ao alagamento intermitente. No entanto, estudos básicos de caracterização dos seus mecanismos de tolerância ainda são pouco conhecidos, mas podem trazer importantes informações sobre a espécie. Objetivouse, portanto, estudar os efeitos de baixas concentrações de oxigênio, induzida por alagamento, sobre o metabolismo de carboidratos e as características anatômicas em plantas de sibipiruna, visando a obter dados que auxiliem na seleção de plantas promissoras para a revegetação de áreas alagadas.

\section{MATERIAL E MÉTODOS}

Sementes de sibipiruna cedidas pelo Departamento de Engenharia Florestal da Universidade Federal de Lavras (UFLA) foram submersas em hipoclorito $50 \%$ por um minuto, lavadas em água destilada e envolvidas em papel de germinação, 25 por rolo, embebido em solução de Benlat $1 \%(\mathrm{p} / \mathrm{v})$, para evitar a proliferação de fungos, e mantidas em câmara de germinação úmida a $25 \pm 2^{\circ} \mathrm{C}$, no escuro. Após oito dias, quando a radícula apresentava aproximadamente $5 \mathrm{~cm}$, estas foram transferidas individualmente para sacos de polietileno de $7 \mathrm{~cm}$ de diâmetro por $20 \mathrm{~cm}$ de altura, contendo como substrato Plantmax. As mudas foram mantidas em casa de vegetação localizada no Departamento de Biologia, Setor de Fisiologia Vegetal da UFLA. Ao atingirem três a quatro folhas completamente expandidas, as plantas foram submetidas a três tratamentos: plantas sem alagamento, alagadas nas raízes (nível da água $2 \mathrm{~cm}$ acima do substrato, totalizando uma lâmina de aproximadamente $25 \mathrm{~cm}$ ) e totalmente alagadas (lâmina de água de aproximadamente $70 \mathrm{~cm}$ ). Os tratamentos foram realizados em tanques de alvenaria cobertos com sombrite $50 \%$ de sombreamento para as plantas, durante 30 dias, e a cada cinco foram realizadas coletas de plantas de cada tratamento para análises posteriores.

O índice de sobrevivência foi avaliado em cinco plantas por tratamento. Essas plantas foram retiradas dos tanques e mantidas em casa de vegetação, onde, após 15 dias, a sobrevivência foi avaliada pela emissão de novas folhas e/ou brotos. A massa seca total foi determinada em três plantas por tratamento. As plantas foram coletadas, suas raízes lavadas e postas para secar em estufa de ventilação forçada até atingirem peso constante e logo pesadas. 
Para a avaliação dos carboidratos em folhas e raízes, $50 \mathrm{mg}$ de massa seca de cada tecido de três plantas por tratamento foram homogeneizados em $2 \mathrm{~mL}$ de água. Em seguida, foi feito banho-maria por 30 minutos, a $40^{\circ} \mathrm{C}$. O homogenato foi centrifugado a 5.000 $\mathrm{X} g$ por 20 minutos, coletando-se o sobrenadante. $\mathrm{O}$ processo foi repetido por duas vezes, e os sobrenadantes combinados. Para a extração do amido, o pellet da centrifugação anterior foi ressuspendido com $8 \mathrm{~mL}$ do tampão acetato de potássio $200 \mathrm{mM}$, pH 4,8 e colocado em banho-maria $\left(100^{\circ} \mathrm{C}\right)$, por cinco minutos. Em seguida, foram adicionados $2 \mathrm{~mL}$ da solução da enzima amiloglucosidase (Sigma), contendo 12,6 unidades e novamente incubado em banho-maria a $40^{\circ} \mathrm{C}$, por duas horas. Após a centrifugação a $5.000 \mathrm{X}$ $g$ por 20 minutos, o sobrenadante foi coletado, e o volume completado com água ultra pura para $15 \mathrm{~mL}$.

Os açúcares solúveis totais (AST) e o amido foram quantificados pelo método da Antrona (DISCHE, 1962), e para os açúcares redutores (AR) seguiu-se o protocolo descrito por MILLER (1959). Nas plantas totalmente alagadas, as avaliações nas raízes foram realizadas até 25 dias após o início do experimento e nas folhas somente até 15 dias, uma vez que, após esse período, as plantas desse tratamento haviam perdido totalmente suas folhas.

As características anatômicas foram avaliadas 15 dias após o início do experimento, quando folhas e raízes das plantas em cada condição de crescimento foram coletadas e conservadas em álcool 70\% GL. Utilizou-se micrótomo de mesa para a obtenção das seções transversais das raízes realizadas a $4 \pm 0,5 \mathrm{~cm}$ do ápice, e os cortes paradérmicos foram efetuados manualmente no terço médio das folhas, na epiderme abaxial, uma vez que essa espécie apresenta estômatos somente nessa face. Após clarificadas em hipoclorito de sódio a 5\%, por dois minutos, com posterior lavagem tríplice em água destilada, as seções transversais foram coradas com uma mistura de azul de astra e safranina, e as paradérmicas, com solução de azul de toluidina $0,2 \%$. Glicerina 50\% foi utilizada na montagem das lâminas.

A densidade estomática foi expressa em número de estômatos por $\mathrm{mm}^{2}$, sendo observados quatro campos por folíolo de cinco plantas por tratamento. As medidas de espessura dos tecidos foram realizadas utilizando-se uma ocular micrométrica acoplada em microscópio de luz, efetuada em cinco plantas por tratamento, com três medidas em diferentes campos de cada tecido. Para o diâmetro polar e equatorial, foram utilizadas cinco plantas por tratamento, sendo medidos, em média, 15 estômatos por planta.
O experimento foi conduzido em delineamento inteiramente casualizado. Os valores de massa seca total e carboidratos foram obtidos da média de três repetições, calculando o erro padrão representado pelas barras de erro. Os dados originais de anatomia foram submetidos ao teste de normalidade e à análise de variância, com o auxílio do sistema SISVAR. As médias dos tratamentos foram comparadas pelo teste de Tukey $(\mathrm{P} \leq 0,05)$.

\section{RESULTADOS E DISCUSSÃO}

Plantas de sibipiruna alagadas nas raízes mantiveram alto índice de sobrevivência até 20 dias após a indução do estresse, aproximadamente 85\%, seguido de uma expressiva queda, chegando a cerca de $12 \%$ aos 30 dias (Figura 1A). Por outro lado, as plantas totalmente alagadas sobreviveram somente até o décimo dia de alagamento, quando apresentaram em torno de $50 \%$ de sobrevivência. Para a massa seca total (Figura 1B), ao final das avaliações, as plantas sem alagamento apresentaram um expressivo incremento, de aproximadamente $700 \%$. As plantas alagadas somente nas raízes também apresentaram crescimento, porém, em menor proporção, em torno de $235 \%$ até os 25 dias, seguido de uma expressiva queda para a última avaliação. Entretanto, o alagamento total teve efeito negativo sobre a produção de massa seca, em que foi observada queda de aproximadamente $41 \%$ do início aos 25 dias de indução do estresse. A redução na massa seca dessas plantas se deve à intensa queda de folhas já no início da indução do alagamento, interferindo diretamente na produção total de massa.

É comum a redução da massa seca da parte aérea em plantas submetidas a condições de hipoxia, fato observado em soja (SORTE et al., 1995), trigo e feijão (SINGH et al., 1991). A sobrevivência da sibipiruna ao alagamento parcial ou total está diretamente relacionada à produção e/ou manutenção de folhas durante o período de estresse. Dessa forma, a maior ou menor tolerância pode ser devido à produção de compostos carbonados por meio da fotossíntese, uma vez que, no estádio em que se encontravam, os cotilédones já haviam caído.

Os teores de amido apresentaram expressiva variação entre os tratamentos. Nas folhas, a maior diferença entre o tratamento não alagado e alagado nas raízes foi observada na última avaliação, redução de 41,45\% no tratamento alagado (Figura 1- C1). Nas plantas totalmente alagadas, a maior diferença para os demais tratamentos foi observada aos cinco dias, redução de 65,49\% em relação às plantas não alagadas e de 59,53\% em relação às alagadas nas raízes. Nas 


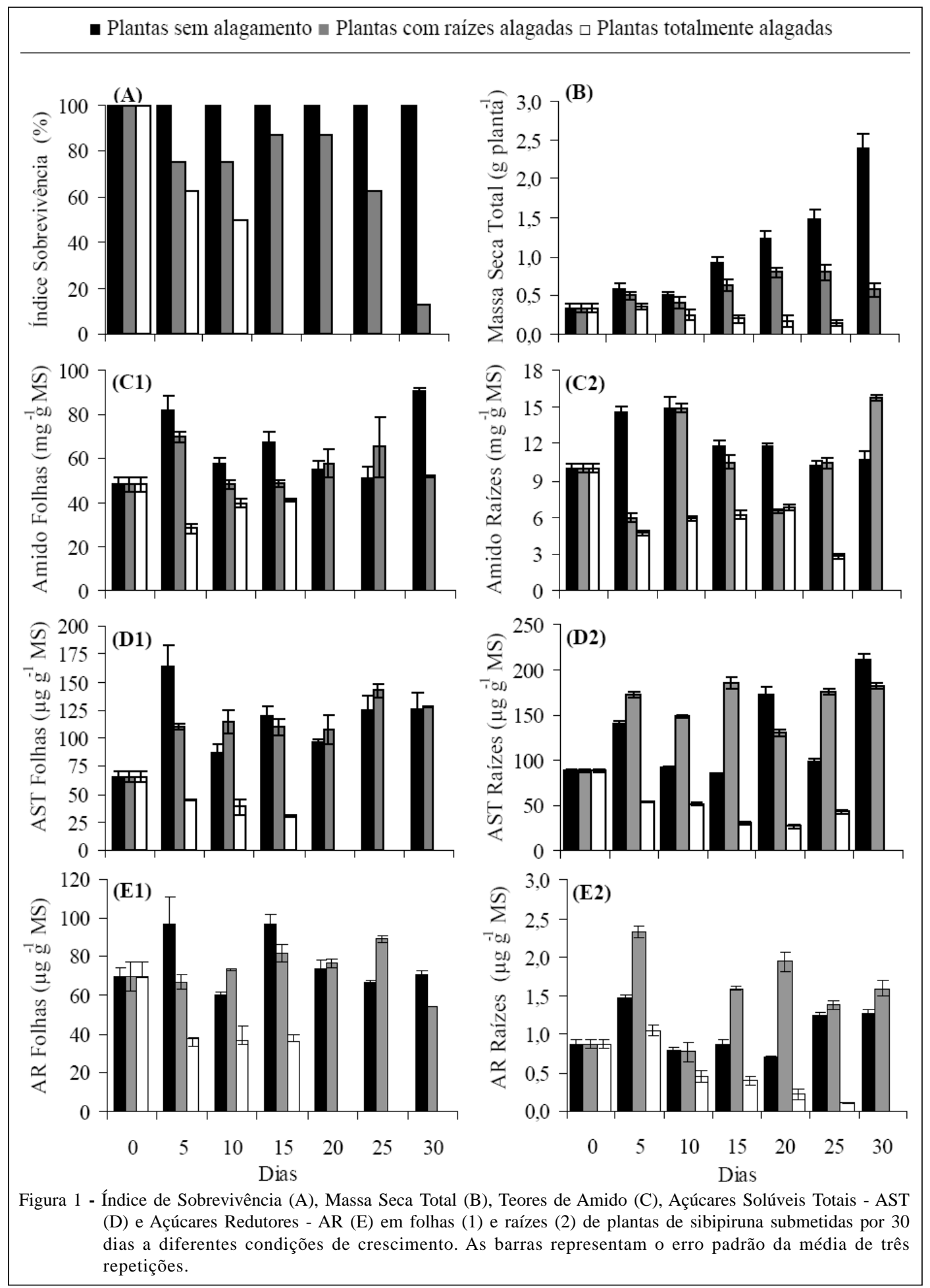

raízes (Figura 1- C2), os teores de amido foram expressivamente inferiores, em que aos cinco e 20 dias as plantas alagadas nas raízes apresentaram redução de 59,04\% e 45,05\%, respectivamente, em relação ao tratamento não alagado. Para as plantas totalmente alagadas, a partir do quinto dia, houve uma expressiva diminuição em amido, sendo o menor valor observado aos 25 dias, com queda de aproximadamente 73\%.

Os açúcares solúveis totais (AST) nas folhas apresentaram redução nas plantas alagadas nas raízes 
em relação às controle somente aos cinco dias de estresse (Figura 1 - D1). Nos demais períodos, não foram observadas variações expressivas. Já as plantas totalmente alagadas, em todos os períodos avaliados, apresentaram valores inferiores aos demais tratamentos, sendo a maior diferença em relação ao não alagado observada aos 15 dias, redução de 74,15\%. Nas raízes, os menores teores em AST também foram observados para as plantas totalmente alagadas (Figura 1 - D2). Entretanto, as alagadas nas raízes apresentaram teores de AST superiores às não alagadas aos cinco, 10, 15 e 25 dias de avaliação.

Os teores de açúcares redutores (AR) nas folhas e nas raízes (Figura 1 - E1 e E2) apresentaram a mesma tendência observada em AST. Comparando o tratamento não alagado ao alagado nas raízes, principalmente para as avaliações realizadas nas raízes, também foi observado que, sob alagamento, houve aumento em alguns períodos de avaliação, nos teores de AR, assim como observado em AST. Já nas plantas totalmente alagadas houve uma redução expressiva em AR em relação aos demais tratamentos.

A redução na respiração das raízes é uma das primeiras respostas das plantas sob anoxia, cuja atividade metabólica é inibida, e a produção de ATP decresce, restringindo o fornecimento de energia para o crescimento das raízes e reduzindo, assim, o crescimento vegetativo (BATISTA et al., 2008). Entretanto, o acúmulo de açúcares solúveis em raízes de plantas sob alagamento do solo tem sido reportado como forma de tolerância a esse estresse. No presente experimento, foi observado aumento na taxa de crescimento até 25 dias nas plantas alagadas nas raízes com índice de sobrevivência de $85 \%$ aos 20 dias, indicando uma eficiente atividade fotossintética para a produção de carboidratos para essas plantas, o que pode estar relacionado a sua maior tolerância ao alagamento. Esse fato não foi observado nas plantas submetidas ao alagamento total.

Outras características muito variáveis em plantas de acordo com o ambiente são a densidade e o tamanho dos estômatos. As plantas de sibipiruna apresentaram aumento significativo na densidade estomática quando submetidas ao alagamento das raízes (Tabela 1). Essa pode ser uma estratégia utilizada para as plantas aumentarem suas taxas fotossintéticas e assim melhor tolerarem a condição de estresse, sendo uma característica importante para seleção de plantas tolerantes ao alagamento (BATISTA et al., 2008). Para o diâmetro polar e equatorial dos estômatos, não houve variação significativa entre os tratamentos estabelecidos. MELO et al. (2004) observaram que, apesar de não ter havido diferença significativa entre os tratamentos, folhas de plantas de milho submetidas ao alagamento apresentaram valores de densidade estomática ligeiramente superiores às plantas não alagadas.

Para a espessura dos tecidos radiculares, não houve diferença significativa a epiderme, apesar de ser um tecido bastante responsivo às alterações das condições do ambiente. Por outro lado, o córtex e o cilindro vascular, nas plantas submetidas ao alagamento, apresentaram significativa redução em suas espessuras em relação ao controle (Tabela 1). MELO et al. (2007) observaram que plantas de Setaria anceps e Paspalum paniculatum, em condições de deficiência hídrica, também não apresentaram diferença significativa na espessura da epiderme em folhas e em raízes. Entretanto, verificaram diminuição da espessura do córtex radicular. É sabido que o alagamento do solo pode levar a condições de déficit hídrico nas plantas, em razão da redução do metabolismo respiratório das

Tabela 1 - Densidade estomática, diâmetros polar e equatorial de estômatos e espessura de tecidos radiculares em plantas de sibipiruna submetidas ao alagamento durante 15 dias.

\begin{tabular}{|c|c|c|c|c|c|c|}
\hline \multirow{3}{*}{ Características avaliadas } & \multirow{2}{*}{\multicolumn{2}{|c|}{ Plantas sem alagamento }} & \multirow{2}{*}{\multicolumn{2}{|c|}{ Plantas com raízes alagadas }} & \multirow{2}{*}{\multicolumn{2}{|c|}{ Plantas totalmente alagadas }} \\
\hline & & & & & & \\
\hline & Folha & Raiz & Folha & Raiz & Folha & Raiz \\
\hline Dens. Est. Ab. $\left(\mathrm{n}^{\circ} / \mathrm{mm}^{2}\right)$ & $89,6 b^{*}$ & - & $134,2 \mathrm{a}$ & - & $86,6 \mathrm{~b}$ & - \\
\hline DPEEAb $(\mu \mathrm{m})$ & 70,8 a & - & 71,9 a & - & 73,3 a & - \\
\hline DEEEAb $(\mu \mathrm{m})$ & 50,5 a & - & 51,4 a & - & 52,2 a & - \\
\hline Epiderme $(\mu \mathrm{m})$ & - & 12,5 a & - & 13,6 a & - & 12,9 a \\
\hline Córtex $(\mu \mathrm{m})$ & - & $176,6 \mathrm{a}$ & - & $138,1 \mathrm{~b}$ & - & $153,5 \mathrm{~b}$ \\
\hline Cilindro vascular $(\mu \mathrm{m})$ & - & 146,9 a & - & $111,4 \mathrm{~b}$ & - & $100,6 \mathrm{~b}$ \\
\hline
\end{tabular}

Dens. Est. Ab. = densidade estomática da epiderme abaxial; DPEEAb = diâmetro polar dos estômatos da epiderme abaxial; DEEEAb = diâmetro equatorial dos estômatos da epiderme abaxial. * Médias seguidas pela mesma letra, entre os tratamentos, não diferem entre si pelo teste de Tukey $(\mathrm{P} \leq 0,05)$. 
raízes. A depender da plasticidade anatômica, algumas espécies desenvolvem mudanças na espessura de seus tecidos que possibilitam uma melhor adaptabilidade a diferentes condições de estresse.

Além disso, estruturas como aerênquimas são características bastante frequentes em plantas submetidas ao alagamento (DEUNER et al., 2007). Porém, na sibipiruna, não foi observada a sua formação nas raízes. Entretanto, na região do córtex, foi observada a formação de septos nas células próximas à endoderme, os chamados espessamentos em fi (Ø), tanto para o tratamento controle (Figura 2A), quanto para o totalmente alagado (Figura 2B). Porém, no tratamento alagado, evidenciam-se raízes com uma maior barreira apoplástica imposta pelo espessamento em fi relativamente ao controle. Essas células com espessamento semelhante ao das estrias de Caspary se apresentam de forma concêntrica, formando geralmente uma bainha contínua na região cortical da raiz. PIRES et al. (2003), realizando um estudo de separação taxonômica dos gêneros Prosthechea e Encyclia por meio da anatomia das folhas e raízes, observaram que todas as espécies analisadas apresentavam células com espessamento fi com sua ocorrência no córtex. Segundo GERRATH (2002), o espessamento em fi serve de barreira mecânica à saída de água do cilindro vascular em direção à região cortical, mantendo a turgidez celular e possibilitando o crescimento do ápice radicular e o rompimento do substrato pela ponta da raiz. Essa pode ser outra característica importante para espécies vegetais com capacidade de crescerem em ambientes sujeitos ao alagamento, uma vez que o estresse por alagamento pode levar ao estresse hídrico e, assim, a capacidade dessas plantas reterem a água por mais tempo pode aumentar sua tolerância ao estresse.

\section{CONCLUSÕES}

A sibipiruna é uma espécie promissora para a revegetação de áreas de depleção, uma vez que apresenta alto índice de sobrevivência principalmente ao alagamento parcial. A redistribuição de compostos carbonados oriundos da fotossíntese e sua plasticidade anatômica, principalmente pela maior barreira apoplástica imposta pelo espessamento em fi, podem ser características fundamentais para a maior tolerância a condições de alagamento.

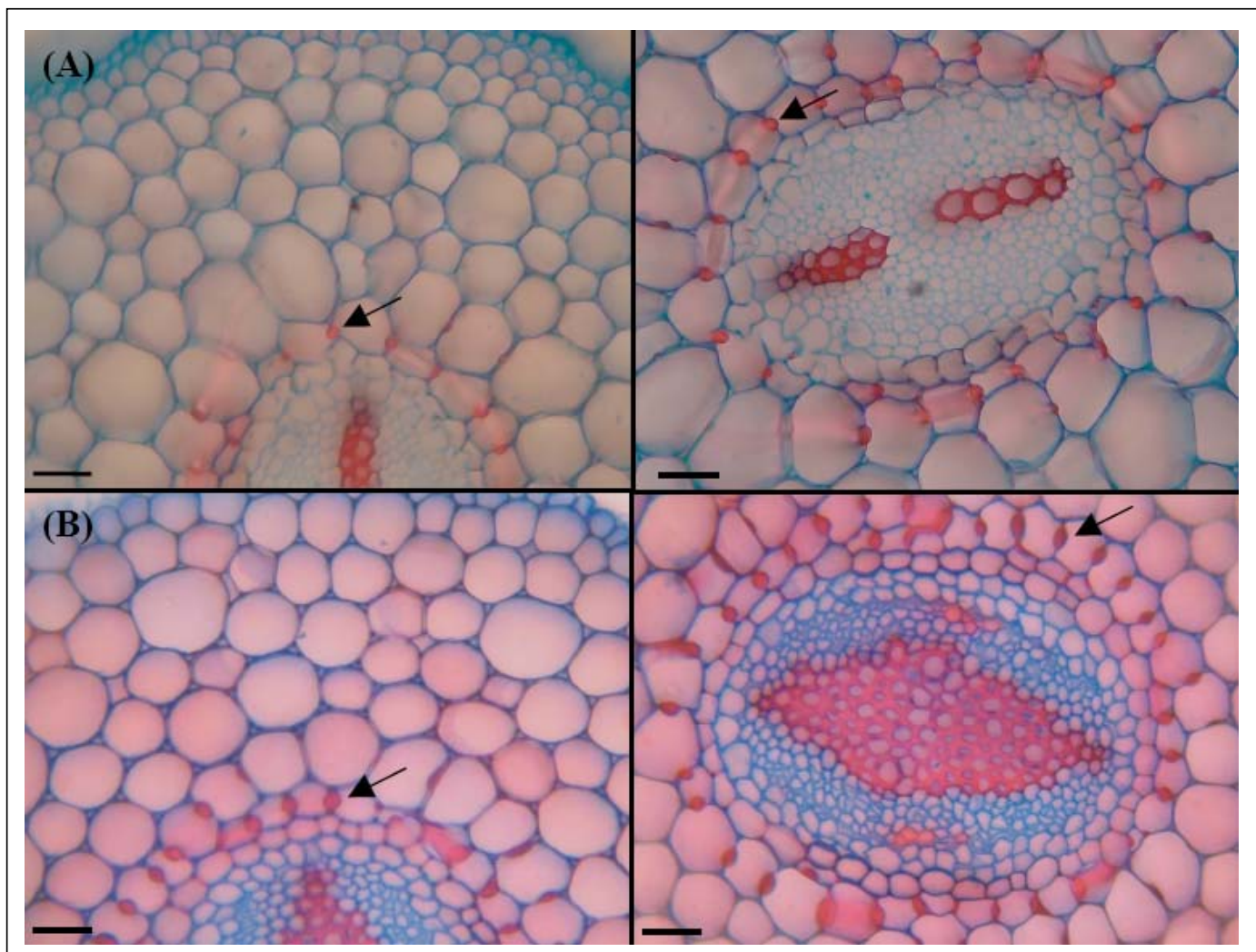

Figura 2 - Fotomicrografias da seção transversal de raízes de plantas de sibipiruna. Plantas sem alagamento (A) e 15 dias após alagamento total $(B)$. (barra $=40 \mu \mathrm{m})$. Seta: espessamento em fi (Ø). 


\section{REFERÊNCIAS}

BATISTA, C.U.N. et al. Tolerância à inundação de Cecropia pachystachya Trec. (Cecropiaceae): aspectos ecofisiológicos e morfoanatômicos. Acta Botânica Brasileira, v.22, n.1, p.91-98, 2008. Disponível em: <http://www.scielo.br/

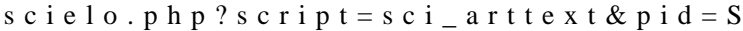
$010233062008000100012 \& \operatorname{lng}=p t \& n r m=i s o>$ Acesso em: 14 jul. 2009. doi: 10.1590/S0102-33062008000100012.

CAPON, S.J. Flood variability and spatial variation in plant community composition and structure on a large arid foodplain. Journal of Arid Environments, v.60, p.283-302, 2005.

DEUNER, S. et al. Respostas anatômicas de plantas de ervade-bicho (Polygonum punctatum Elliot) submetidas ao alagamento. Revista Brasileira de Biociências, Porto Alegre, v.5, supl.1, p.120-122, 2007.

DIAS-FILHO, M.B. Respostas morfofisiológicas de Brachiaria spp. ao alagamento do solo e a síndrome da morte do capimmarandu. In: BARBOSA, R.A. (Ed). Morte de pastos de braquiárias. Campo Grande, MS: EMBRAPA Gado de Corte, 2006. p.83-101.

DISCHE, Z. General color reactions. In: WHISTLER, R.L.; WOLFRAM, M.L. Carbohydrate chemistry. New York: Academic, 1962. p.477-520.

GERRATH, J.M. et al. Occurrence of phi thickenings is correlated with gymnosperm systematics. Canadian Journal of Botany, v.80, n.8, p.852-860, 2002. Disponível em: <http:/ /web.ebscohost.com/ehost/pdf?vid=3\&hid=104\&sid=11af227e8b89-4514-aaf3-12484bd91016\%40sessionmgr104>. Acesso em: 10 jul. 2008. doi: 10.1139/B02-075.

JACKSON, M.B.; COLMER, T.D. Response and adaptation by plants to flooding stress. Annals of Botany, v.96, p.501-505, 2005.
LORENZI, H. Árvores brasileiras: manual de identificação e cultivo de plantas arbóreas nativas do Brasil. 4ed. Nova Odessa - SP: Instituto Plantarum, 2002. V.1.

MELO, H.C. et al. Alterações anatômicas e fisiológicas em Setaria anceps e Paspalum paniculatum L. sob condições de déficit hídrico. Hoehnea, v.34, n.2, p.145-153, 2007.

MELO, H.C. et al. Influência da aplicação de cálcio e alagamento do solo sobre características anatômicas das folhas de milho (Zea mays L.) "Saracura” BRS-4154. Revista Brasileira de Milho e Sorgo, v.3, p.333-342, 2004.

MILLER, G.L. Use of dinitrosalicylic acid reagent for determination of reducing sugar. Analytical Chemistry, v.31, n.3, p.426-428, 1959.

PIRES, M.F.O. et al. Taxonomic separation of the genera Prosthechea and Encyclia (Laeliinae: Orchidaceae) using leaf and root anatomical features. Botanical Journal of the Linnean Society, v.143, p.293-303, 2003.

SALVADOR, J.L.G. Comportamento de espécies florestais nativas em áreas de depleção de reservatório. IPEF, v.33, p.7378, 1986.

SCHAFFER, B. et al. Responses of fruit crops to floodding. Horticultural Review, v.13, p.257-313, 1992.

SINGH. P. et al. Flooding reduces gas exchange and growth in snap bean. Hort Science, v.26, nA, p.372-373, 1991.

SORTE, N.V. et al. Effect of waterlogging on soybean at critical growth stages. Journal of Soils and Crops, v.S, n.2, p.141144, 1995.

ZENZEN, I.L. et al. Influência do alagamento no acúmulo de matéria seca em plantas de soja inoculadas com diferentes estirpes de Bradyrhizobium. In: CONGRESSO DE INICIAÇÃO CIENTÍFICA-UFPel, 15., 2006, Pelotas. Anais... Pelotas: UFPel, 2006. CD-ROM. 